This item was submitted to Loughborough's Research Repository by the author.

Items in Figshare are protected by copyright, with all rights reserved, unless otherwise indicated.

\title{
Improving children's written grammar and style: revising and editing with
} \section{HARRY}

PLEASE CITE THE PUBLISHED VERSION

PUBLISHER

(C) Elsevier

LICENCE

CC BY-NC-ND 4.0

REPOSITORY RECORD

Holdich, C.E., Paul Wai Hing Chung, and R.G. Holdich. 2006. "Improving Children's Written Grammar and Style: Revising and Editing with HARRY". figshare. https://hdl.handle.net/2134/2349. 
This item was submitted to Loughborough's Institutional Repository by the author and is made available under the following Creative Commons Licence conditions.

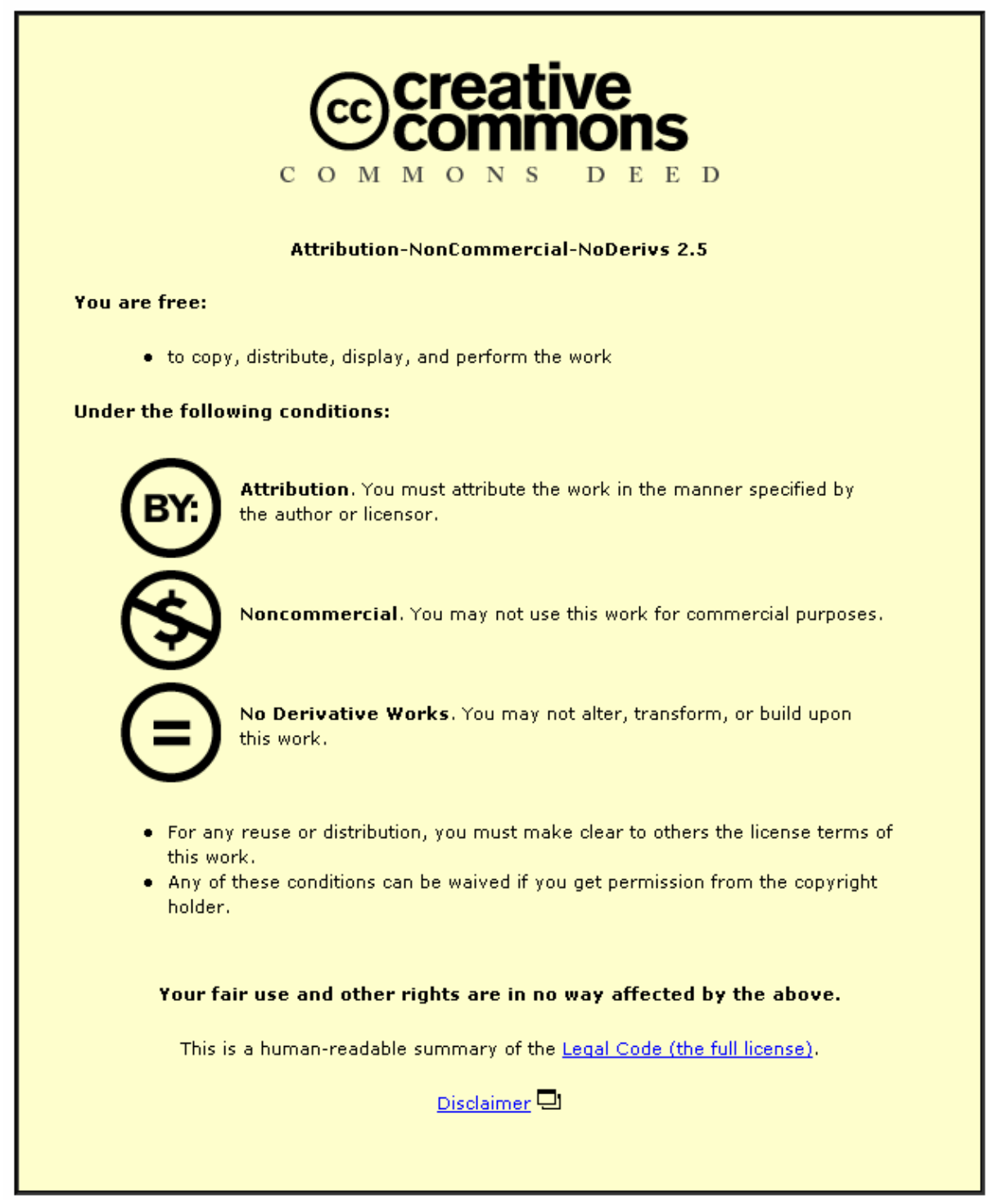

For the full text of this licence, please go to: http://creativecommons.org/licenses/by-nc-nd/2.5/ 


\title{
Improving children's written grammar and style: revising and editing with HARRY
}

\author{
C.E. Holdich, P.W.H. Chung and R.G. Holdich \\ Department of Computer Science, \\ Loughborough University, \\ Leics. LE11 3TU. UK
}

Email: p.w.h.chung@lboro.ac.uk

\begin{abstract}
Children usually improve their writing in response to teacher comments. HARRY is a computer tutor, designed to assist children improve their narrative writing, focusing particularly upon grammar and style. Providing assistance involved identifying aspects of grammar and style on which to concentrate, including ways to enable the computer to detect weaknesses and then present information concerning how to make improvements. HARRY delivers general, conversational style suggestions for how to revise a text during composition, followed by editing suggestions targeting specific grammar and style weaknesses detected in the text. Finally, spellings and technical errors are corrected in MS Word. Evaluating a writing intervention strategy is problematic, as paradoxically, attempts by children to improve texts, can result in a deterioration in some aspects of writing quality. Four case studies are presented to demonstrate the effects of the HARRY writing system upon children's grammar and style. Each child wrote a control and a HARRY assisted story. HARRY's effectiveness at improving written grammar and style is demonstrated through analyses made of the narratives by CHECK TEXT, a utility tool which calculates and interprets quantitative data. Separate analysis of each stage of the HARRY assisted stories reveals the idiosyncratic pattern of improvement exhibited by each child.
\end{abstract}

Keywords: hypermedia systems, elementary education, improving classroom teaching, teaching strategies, evaluation methodologies

\section{Introduction}

For mature writers, writing is essentially rewriting (Murray, 1984). Revision is the means by which a text is gradually improved. Children however, rarely initiate revisions to their writing, whether they are using pencil and paper or a word processor. Most children merely proof read at a superficial level focusing on spelling (Bereiter and Scardamalia, 1983). Studies such as Hillocks (1982) and Trushell (1986) indicate that children only attempt to revise their writing in response to external evaluations provided by either peers or teachers. Trushell (1986) found that collaborative writing had the effect of moving children towards achieving more sophisticated writing, whilst Hillocks (1982) noted that children produced better stories when they revised in response to teacher questions directed at specific features. Other studies indicate that helping children to learn how to improve their own writing is not an easy task. Harpin's (1976) study, demonstrating how children's writing changed through primary school, using measures such as word counts and sentence and clause lengths, revealed that some children appear to advance very little over considerable periods of time. Bereiter and Scardamalia (1987) noted how their most successful experiments in affecting children's composing processes did not lead to discernible improvements, as judged by impressionistic ratings. Assessing the effectiveness of writing intervention strategies is also problematic however. Karmiloff-Smith (1992) observed that attempts by children to improve 
their writing, by reflecting upon it, can result in the opposite effect - a drop in writing quality. Sharples (1999, p.29) describes the process of gaining the ability to reflect as a 'U-shaped learning curve'. Reflection can lead a child to the bottom of the curve, but be insufficient to help the child up the other side. There may be several causes of this phenomenon. Reflecting upon performance may take up valuable mental space and disrupt the child's flow of ideas. Alternatively, the child may try to implement writing techniques or strategies without fully understanding how to apply them successfully. The paradox has important implications for the evaluation of a computer tool aiming to help children improve writing quality. Merely regarding higher statistical scores as evidence of improvement for instance, would clearly be inadequate. Attention must be paid to differences in writing quality, not simply 'improvements'.

This paper details the design and evaluation of HARRY - a computer tool aiming to assist children improve their narrative writing, focusing particularly upon grammar and style, by encouraging them to revise and edit their texts. Implementation of these features required a review of the research concerning the differences in grammar and style between mature and beginner writers, reasons why children experience difficulties with revision and editing, effective teaching methods for helping children improve grammar and style, and previous systems which have facilitated revising and editing. The effects of the writing tool upon children's written grammar and style are evaluated using a specially designed utility tool CHECK TEXT - designed to compare children's written grammar and style to national standards. Four case studies are presented. The studies demonstrate the idiosyncratic pattern of improvement exhibited by each child.

\subsection{Comparison of written grammar and style between mature and beginner writers}

Perera (1984) and Kress (1994) have identified many differences between the written grammar and style of mature and beginner writers. Young children characteristically use simple vocabulary such as 'big', 'nice', 'said', 'went', 'saw', 'got' etc. They record their thoughts and ideas in simple sentences and frequently exhibit excessive repetition of the same subject pronoun such as I...I...I or He...He...He, which results in a monotonous writing style. Compound sentences are also a feature of young beginner writers with sentences often linked by several 'and's or 'and then's. Very young children are resistant to using any punctuation (Hall, 1998).

Mature writing is evidenced by varied and sophisticated vocabulary. Words are chosen to convey precise shades of meaning. Over use of simple connectives such as 'and' is avoided by replacing an 'and' with a full stop and beginning a new sentence, substituting an alternative connective for 'and' such as 'when' or 'whilst' etc., or by substituting a comma. Mature writing is further characterised by the presence of a variety of sentence constructions, achieved by creating different clause structures, by using different kinds of sentences (statements, questions, exclamations etc.) and by using different types of sentences (minor, simple, compound or complex). Although mature writers use a greater proportion of complex sentence constructions than beginner writers do, they recognise that there is no virtue in complexity for its own sake. Short, simple sentences are interspersed between longer, more complex sentence constructions when writing a narrative, to achieve particular effects - short sentences can add suspense whilst long sentences comprised of several clauses, can enhance descriptions. In addition, mature writers punctuate their writing accurately. By displaying the grammatical structure, they make their texts clear for others to read. 


\subsection{Children's difficulties with revision}

Children's general lack of revision is due, not to reluctance on the part of the young writers to make changes to their own drafts, but to the inherent difficulties involved with the task. Researchers account for the difficulties in different ways. Research based on Piagetian (1926) theories of cognitive development, such as Bereiter and Scardamalia (1987) suggests there may be certain cognitive limits on the skills that even practised children can acquire. With this view, children's revision problems are seen to stem from an inability to represent an event from two points of view - their own and that of the reader. Only when children's egocentrism eventually diminishes will they learn to maintain two points of view and make decentred comparisons between them.

Other researchers such as Bartlett (1982) suggest an alternative reason for why children are unable to revise - revision involves two key processes: detecting (which includes identifying) a problem followed by the ability to successfully correct it. For mature writers, detection and correction are performed simultaneously, but for beginner writers, difficulties can arise in either of the processes. Children may comment that "this isn't right", but be unable to correct the problem or be able to correct a problem, but only if directed to it. In order to detect a problem, writers must achieve a detachment from their work that allows them to see what is on the page, not what they hope will be on the page. The writer must inhibit interpretations based on knowledge of the writer's own intentions, such as with the statement "that's his brother", where "his" means Sam! This is privileged knowledge known only to the writer. As writers do not have privileged information about texts composed by others, they will not be faced with the problem of inhibiting it. Bartlett's (1982) study suggests that this is the reason why children find it easier to detect problems in the texts of others rather than in their own. For children, detection is a haphazard process however, often proceeding without wellplanned goals or strategies, and sometimes hampered by poor reading skills.

Success in correcting a text problem depends on adequate detection processes, but these need not necessarily lead to an appropriate correction. The children involved in Bartlett's study were frequently able to detect grammatical problems which they could not successfully correct. Beginner writers may lack knowledge of a range of devices and may rely on familiar ones regardless of their appropriateness. They may also make decisions based on other, more mechanical constraints, such as knowing how to delete and insert material, or conversely, not knowing how to do this. Potter (1994) believed that the problem could be rectified by children having greater access to word processors (achieved by allocating children with cheap, personal, portable laptops), resulting in greater familiarity with the redrafting facilities. Teaching children how to make changes to a text is distinctly easier than helping them to reflect upon their text and see when changes are appropriate however.

\subsection{Teaching methods}

Pupils have not been explicitly taught grammar for several decades. It was assumed that grammar teaching did not improve children's writing, a legacy of Wilkinson's (1971) review of studies concerning grammar teaching, from which he concluded that the claims for grammar teaching were without 'foundation'. It is only recently that this belief has been reconsidered, prompted largely by Tomlinson's (1994) study, which drew attention to the weaknesses in some of the studies reviewed by Wilkinson. The current approach to teaching grammar is based upon the work of linguists such as Crystal (1995) who recognise the limitations of grammar teaching which concentrates on discrete 'naming of parts' and parsing 
in decontextualised text-book form. Instead, there is a concern with how different sentence structures, and the use of different words and phrases within the various parts of sentences, add interest and reflect particular genre features.

Helping children to acquire vocabulary presents an enormous challenge to teachers. Shaughnessy's (1977) research indicates that there appear to be stubborn and individually different limits to the pace at which words enter pupils' active vocabulary. She suggests that pupils benefit from experiencing the process of discriminating between words, thereby discovering the qualities of their ideas, through activities such as: substitution (taking words from the pupils' own writing and asking them to list alternative synonyms) and looking at the first drafts of others to see how the writers 'debated' word choice.

How to best encourage children to move away from repeatedly using similar sentence constructions which depend upon basic connectives (especially 'and') presents teachers with another challenge. O'Hare (1973) and Shaughnessy (1977) suggest that 'sentence combining activities' can facilitate improvements in writing, as well as provide insights into grammatical structures. O'Hare suggests activities such as, turning statements into questions, combining sentences using a variety of connectives e.g. if, with, what, when, as, etc. and combining sentences by using the verb in its 'ing' form. Shaughnessy recommends activities such as, changing simple sentences to compound or complex sentences and changing complex sentences to simple.

Punctuation can also be difficult to convey, although teachers find some punctuation marks easier to explain than others (Robinson, 1996). Children usually enjoy using exclamation marks and adopt them readily - particularly exclamation marks used to punctuate one word, such as 'Help!' Question marks are considered relatively easy to explain - if someone asks a question, starting with a word such as 'Who', 'Which', 'Where' etc., it is fairly apparent to children where the question ends. Speech marks are also regarded as being within the grasp of most children - speech bubbles are commonly used to demonstrate where they are required. More difficulty is experienced when trying to teach young children when to use full stops and commas. The central problem is that although linguists readily define 'a sentence', young children have no notion of the concept of 'a complete sentence'. Consequently, learning how to punctuate a sentence is a slow developmental process.

The main explanations used by primary teachers for where to place full stops are pausing and intuition (Robinson, 1996). Children are frequently told to put a full stop where they can hear a long pause in a sentence or 'where you take a breath'. A long pause indicates the need for full stop, a short pause indicates a comma. There are two problems with these explanations. First, there is an inconsistent relationship between pausing and punctuation. Oral speech does not always have pauses between those items which would in written language be seen as the boundaries between sentences, while it often does have pauses where no punctuation would be placed in written language. The second problem is that it relies on the child being able to hear the pauses, or lack of pauses, when reading the text. However, a child's own reading may not provide a good model - some children scan ahead whilst reading and know where to take a breath, whereas others take a breath anywhere, even if it is not at the end of a sentence. Some teachers accept the difficulty of these explanations and try to get children to 'feel' a sentence. This is attempted by giving children good experience of reading texts with punctuation, through correction, partly through exercises asking children to place full stops in written text and partly through demonstrations on the board. The expectation is that children will develop intuition for what counts as a sentence. 
How the teaching approaches outlined above are presented is crucial. It is clear that children are more likely to employ correct punctuation, adventurous and sophisticated vocabulary, and a variety of sentence constructions including complex sentences, if they are taught these aspects in the context of their own writing, rather than through the use of drills and exercises (Crystal, 1995). Computer use alone does not increase a child's willingness or ability to revise and edit simply because it makes the tasks easier by having the capacity to rearrange texts, delete and insert words or suggest alternative synonyms contained in a thesaurus etc. (The National Writing Project, 1990). Therefore, word processing tools need to be supplemented with strategies designed to help children improve their texts. Although mature writers sometimes edit their texts during the composition process, for children, editing is best left until after the text content and organisation has been completed, as preoccupation with achieving correct grammar (including spelling) can interrupt and stifle children's flow of ideas (Smith, 1982). Moreover, teachers who concentrate on grammar skills at the expense of content may actually be doing their pupils a disservice when it comes to learning punctuation (Cordeiro, Giacobbe \& Cazden, 1983).

\subsection{Alternative systems}

Text analysis applications such as 'Writer's helper for Windows' carry out objective, statistical analyses of features such as word frequencies and sentence lengths. The applications are targeted at adults however, who are expected to be already highly competent at writing, as they highlight for instance: split infinitives, weak phrases, percentage of abstract words, percentage of passive sentences and readability scores. Writers are expected to interpret the significance of the statistics, using the information to improve their texts accordingly. Text analysis is usually regarded as unsuitable for children, as much of the available statistical information is inappropriate and the method of presentation is likely to be meaningless to them. Word processors such as MS Word offer some assistance by providing grammar checks, but as with text analysis applications, the help provided, such as highlighting sentences longer than 50 words and extra spaces inserted between words etc., is targeted at an adult audience.

The approaches adopted by two alternative systems, specifically aiming to assist children develop revising and editing skills, are presented here. CATCH (Daiute, 1985) was an application designed for young adolescent writers. At any stage of the composing process, the writer could request assistance. The system presented comments or questions one at a time, some of which were based on pattern analyses related to the sentence structure and punctuation of the text, for example the detection of empty words such as 'sort of' and 'well' resulted in the prompt: 'the highlighted words may not be necessary. Do you want to make changes?' Other prompts were concerned with revising the content of the text, for example: 'How can I make my character seem more real?' Daiute reported that the system was largely unsuccessful. Although the students made more changes to the texts, the changes did not necessarily result in improvements. CATCH's lack of success may have been due to prompts being insufficiently explicit at explaining how to make effective changes and a failure to highlight significant features, which when corrected, would result in improvements.

StoryStation (Robertson and Wiemer-Hastings, 2002) aimed to encourage children to review and revise their writing through the provision of two types of support: tools and feedback. The tools were, a dictionary, a thesaurus, word banks and a word count facility. These were intended to help children while they were planning or composing their stories. Two kinds of 
feedback were provided: negative feedback designed to highlight mistakes and positive feedback which highlighted 'good' aspects of writing. The negative feedback was limited to spelling mistakes and overuse of the basic connectives and, but and because. The positive feedback was restricted to characterisation. It included: 'good' vocabulary, dialogue, character descriptions and descriptions of character's feelings and personality. The feedback was colour coded, giving the text the appearance of having been highlighted with coloured felt pens. Spelling mistakes were coloured orange and basic connectives were coloured red. Positive feedback concerning characterisation was coloured grey, green, blue and pink. The feedback was generated by comparing skills evident in the story with skills demonstrated in previous stories. The study indicated that some pupils were confused by the inclusion of positive advice alongside negative advice. In addition, the children quickly discovered that they only needed to respond to the aspects highlighted in red and orange - spelling mistakes and overuse of basic connectives.

The main limitation of both CATCH and StoryStation was that although the systems encouraged revision and identified weaknesses, neither system made it clear to children how to make improvements. The research literature indicates that children require assistance with learning effective revision strategies, such as debating word choice and varying sentence constructions. They also require assistance with detecting, identifying and correcting significant grammar and style weaknesses, such as overuse of the basic connective 'and', lack of full stops, and simple and repetitive vocabulary. For children, it is best if revising and editing are separated into different stages. A new computer tool - HARRY - is currently being developed, aiming to fulfil these design criteria.

\section{HARRY}

HARRY separates the writing process into three stages. During stage one, children are encouraged to revise as they compose a narrative. At stage two, HARRY detects grammar and style weaknesses and suggests ways of editing the text. Spelling and technical errors are corrected at the third stage, when the narrative has been transferred to MS Word. At present, HARRY offers assistance with four story themes: space, pirates, woodland adventure and an enchanted journey. The screen design for stage 1 is presented in Figure 1.

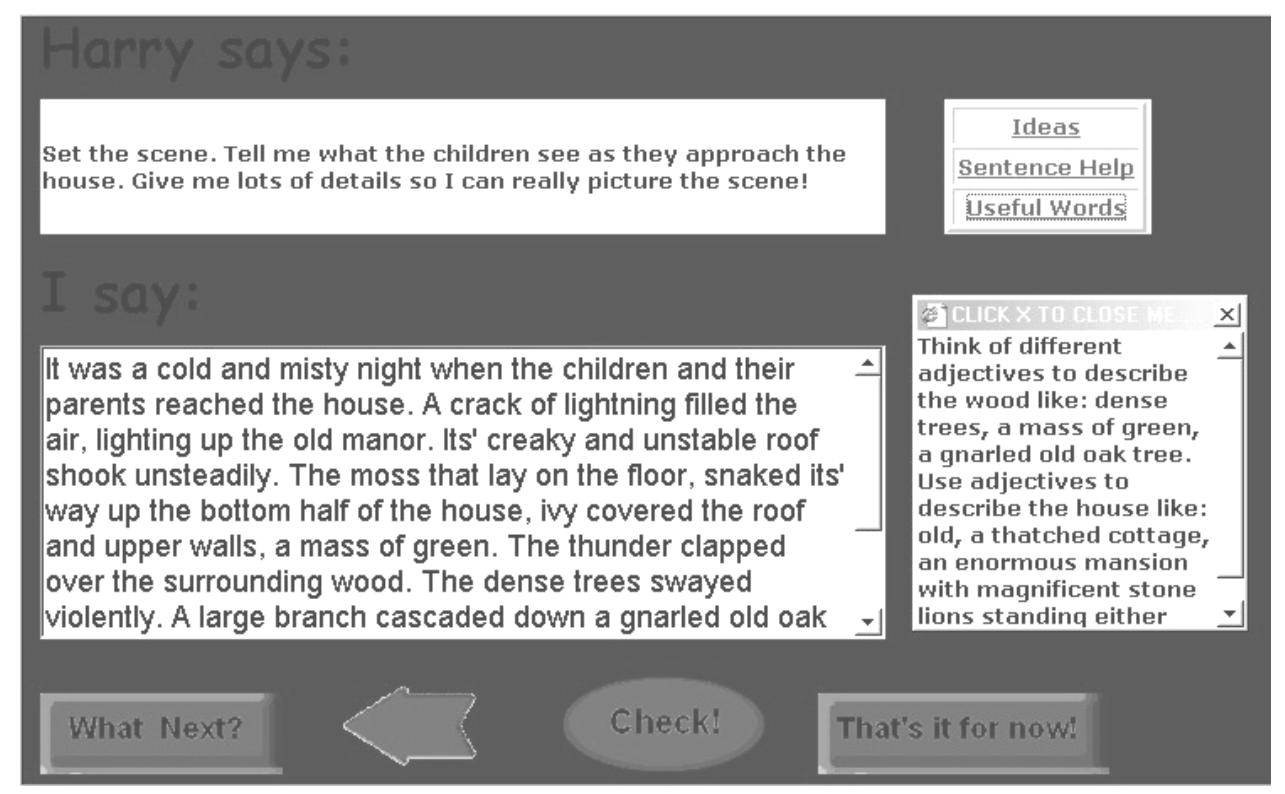

Figure 1. Stage 1: Composing/Revising screen with word help pop-up box open 
During the first stage, written prompts are presented when requested by children, before, during and after they write. Some prompts guide the structure of the narrative; others encourage children to continually revise their writing. A strategy table ensures that each story is structured logically. Each story is divided into sections such as: start, setting, character, action, complication, last. The order of the sections is different for each story because the strategy is flexible. Children are expected to compose their story, working on a section of the story at a time, in response to guiding prompts presented to them, such as:

Start: 'Try starting your story with the children talking as they pack to go on holiday'. Character: 'Tell me more about the children in your story. What are they like?'

Setting: 'Get the children to explore the wood. Describe what it is like there'.

Action: 'Perhaps the children make a discovery! Make this part as exciting as you can!'

Complication: 'I have a feeling something will go wrong in your story soon! But may be things don't turn out to be quite as bad as they first seemed.'

Last: 'You've got to the last part of your story already. Explain what happens as a result of the adventure'.

Children move on to the next section of the story by clicking on the 'What Next?' button. They can move backwards and forwards between completed sections by clicking on the arrow buttons and they can temporarily stop writing by clicking on the 'that's it for now!' button. As they compose, children can request additional suggestions by clicking on the 'help' buttons 'ideas', 'sentence help', 'useful words' and 'check'. The suggestions accessed by these buttons appear in pop up boxes. The help pop up boxes aim to encourage children to review and revise their writing. The boxes can be viewed in any order and any number of times. The ideas help contains suggestions for developing the plot. For example, if the guiding prompt suggests the characters in the story make an exciting discovery, the ideas pop up box will contain appropriate suggestions for plot ideas such as, ' perhaps they could discover a secret tunnel, a den or a secret garden '. The Check help reminds the child to review and revise their text in the ways suggested in the help boxes.

The word and sentence help suggestions are presented in more detail here, as their purpose is to demonstrate constructive ways of improving upon grammar and style whilst composing. Sentence help suggestions encourage children to vary the sentence constructions they use when writing a story (write complex sentences and interweave descriptions with dialogue etc.) by suggesting the writer includes:

- Dialogue - example prompt: 'You can show what someone is like by what they say - like this, "I'll go first," suggested Tim "I'm not scared".

- A question or several questions - example prompt: 'Try to build up a sense of mystery about the house by writing questions, like this, "What was that sound? Do you think it was a door banging?"

- Minor sentences and short punchy sentences - example prompt: 'Write some really short sentences in between long ones like this: He smiled. Of course. That was it! They would have to ...'

- A variety of connectives and prepositions as links between clauses, in order to create varied complex sentences. ' Link descriptions together with words like before, when, whilst, after. Like this: The crazy explorer jumped from one foot to another whilst ...'

- Interesting sentence starters to vary the way sentences are started - example prompt: 'Try one of these sentence starters: At that moment, A thought flashed in his head, Next minute, The next thing that happened ...' 
- Starting a sentence with an adverb to vary the way sentences are started - example prompt: 'Try using adverbs to start your sentences such as: Unfortunately, Fortunately, Luckily, Sadly, Next, Later ...'

- Starting a sentence with a non-finite verb in order to encourage children to vary word order within sentences whilst simultaneously creating complex sentences - example prompt: 'Try starting your next sentence with a verb, like this: Turning the corner, Going closer, Not knowing what it was, Looking up ...'

- Writing similes and metaphors - example prompt: 'Use similes to describe the wood and the house like this: The trees stood close together looking like...To the left, a large house stood silently, as if ...

'Word help' encourages the careful selection of appropriate and sophisticated vocabulary. A list of alternative words relevant to the theme of each section is provided. Word help suggestions aim to extend pupils' vocabulary resources by suggesting:

- Alternative synonyms so that children use words which express their ideas precisely example prompt: 'Remember to say how someone talks. May be they whispered, boasted, interrupted, suggested, or gasped? Do they do this nervously, smiling or quietly?'

- Alternative adjectives and adjectival phrases to assist children in the creation of effective descriptions - example prompt: 'Words to describe the King's palace: polished marble floor, sumptuous red velvet curtains, golden statues, magnificent chandelier shining like..., vast windows as tall as.....

- Alternative connectives to encourage children to experiment with a variety of connectives, rather than the typical limited range comprising and, then, but, so, because etc. Example prompt: 'Here are some good words to link phrases together: although, after, otherwise, since'.

- Alternative adverbs and prepositions so that sentences are sometimes expanded to include the details of 'how' and 'where'. Example prompt: 'You could create a busy feeling. Or everything could be slow and calm. It depends on the adverbs you choose. Do they do things quickly, excitedly, in a rush? Or leisurely, slowly and carefully?' Alternatively, 'Explain where the action took place ... opposite ... outside ... next to ... in the middle of ...'

Several hundred prompts related to the four story themes, are stored in Access databases, categorised into start, setting, character, action, complication, last. Each of these categories is further divided into four fields: ideas help, sentence help, word help and check which store supplementary prompts pertinent to each guiding prompt. Each category contains 4-15 guiding prompts plus the associated help prompts. HARRY randomly presents one guiding prompt (plus the associated help prompts) for each section of the story. Thus, each child receives a different set of prompts. Example guiding prompts plus supplementary help prompts for just the start section of the Space story theme are provided in Table 1 . When writing this section, the child would only view the prompts contained in one row of the table. 
Table 1. Example guiding prompts supported by help prompts

\begin{tabular}{|c|c|c|c|c|}
\hline Guiding prompt & Ideas Help & Sentence help & Word help & Check \\
\hline $\begin{array}{l}\text { A good way to start } \\
\text { your story would be } \\
\text { to describe what it is } \\
\text { like in space. } \\
\text { Perhaps someone is } \\
\text { looking through a } \\
\text { telescope or looking } \\
\text { out from a rocket. }\end{array}$ & $\begin{array}{l}\text { Think about the } \\
\text { darkness, the bright } \\
\text { lights, the silence, } \\
\text { the stillness and the } \\
\text { different planets. }\end{array}$ & $\begin{array}{l}\text { Try writing a simile } \\
\text { like: Deep in space, } \\
\text { it is as silent as.... } \\
\text { distant stars flash } \\
\text { like ....the planets } \\
\text { look like... }\end{array}$ & $\begin{array}{l}\text { unending darkness, } \\
\text { blinding lights, } \\
\text { black expanse, } \\
\text { mysterious, } \\
\text { flickered, dazzled, } \\
\text { glistened, brightly, } \\
\text { slowly }\end{array}$ & $\begin{array}{l}\text { Have you used at } \\
\text { least three words to } \\
\text { describe space? } \\
\text { How about a simile? }\end{array}$ \\
\hline $\begin{array}{l}\text { You could start your } \\
\text { story with a piece of } \\
\text { action - something } \\
\text { which is happening } \\
\text { right now. }\end{array}$ & $\begin{array}{l}\text { Perhaps a rocket has } \\
\text { just been launched, } \\
\text { or is about to land } \\
\text { on a strange planet. } \\
\text { Perhaps someone is } \\
\text { playing a space } \\
\text { computer game. }\end{array}$ & $\begin{array}{l}\text { Try writing some } \\
\text { really short } \\
\text { sentences to make } \\
\text { your opening } \\
\text { exciting like this: } \\
\text { Bang! The control } \\
\text { panel started } \\
\text { flashing. Red alert! }\end{array}$ & $\begin{array}{l}\text { Try using adverbs to } \\
\text { create an exciting or } \\
\text { calm feeling like: } \\
\text { quickly, excitedly, } \\
\text { energetically, } \\
\text { slowly, carefully, } \\
\text { quietly. }\end{array}$ & $\begin{array}{l}\text { Did you make the } \\
\text { mood of this section } \\
\text { clear with the words } \\
\text { you chose? Is it a } \\
\text { noisy, exciting start } \\
\text { or a calm and } \\
\text { peaceful start? }\end{array}$ \\
\hline $\begin{array}{l}\text { Try starting your } \\
\text { story with } \\
\text { something someone } \\
\text { says. They could be } \\
\text { in the middle of } \\
\text { doing something! } \\
\text { What? }\end{array}$ & $\begin{array}{l}\text { Who could be } \\
\text { talking? Someone } \\
\text { building a rocket? } \\
\text { Ground control? An } \\
\text { astronaut? An alien? } \\
\text { Who will reply? }\end{array}$ & $\begin{array}{l}\text { Try writing a } \\
\text { question, or several } \\
\text { questions in a row } \\
\text { like this: What was } \\
\text { that? Did you see it? } \\
\text { Do you think it's a } \\
\text { UFO? }\end{array}$ & $\begin{array}{l}\text { Think of different } \\
\text { words for said like: } \\
\text { called, ordered, } \\
\text { shouted, interrupted, } \\
\text { whispered, asked. }\end{array}$ & $\begin{array}{l}\text { Did you vary your } \\
\text { sentences by writing } \\
\text { some questions? }\end{array}$ \\
\hline
\end{tabular}

When the child has completed the composing stage, working through each section in turn in response to HARRY's prompts, the child's writing is transferred into the editing stage. The editing process is separated into two aspects: grammar and spelling. First, HARRY builds on the assistance provided during the composition stage by providing feedback concerning grammar weaknesses, then the document is transferred into MS Word, where the child is expected to correct spellings and technical errors with the aid of the spell and grammar checkers. The screen design for the editing stage is presented in figure 2.

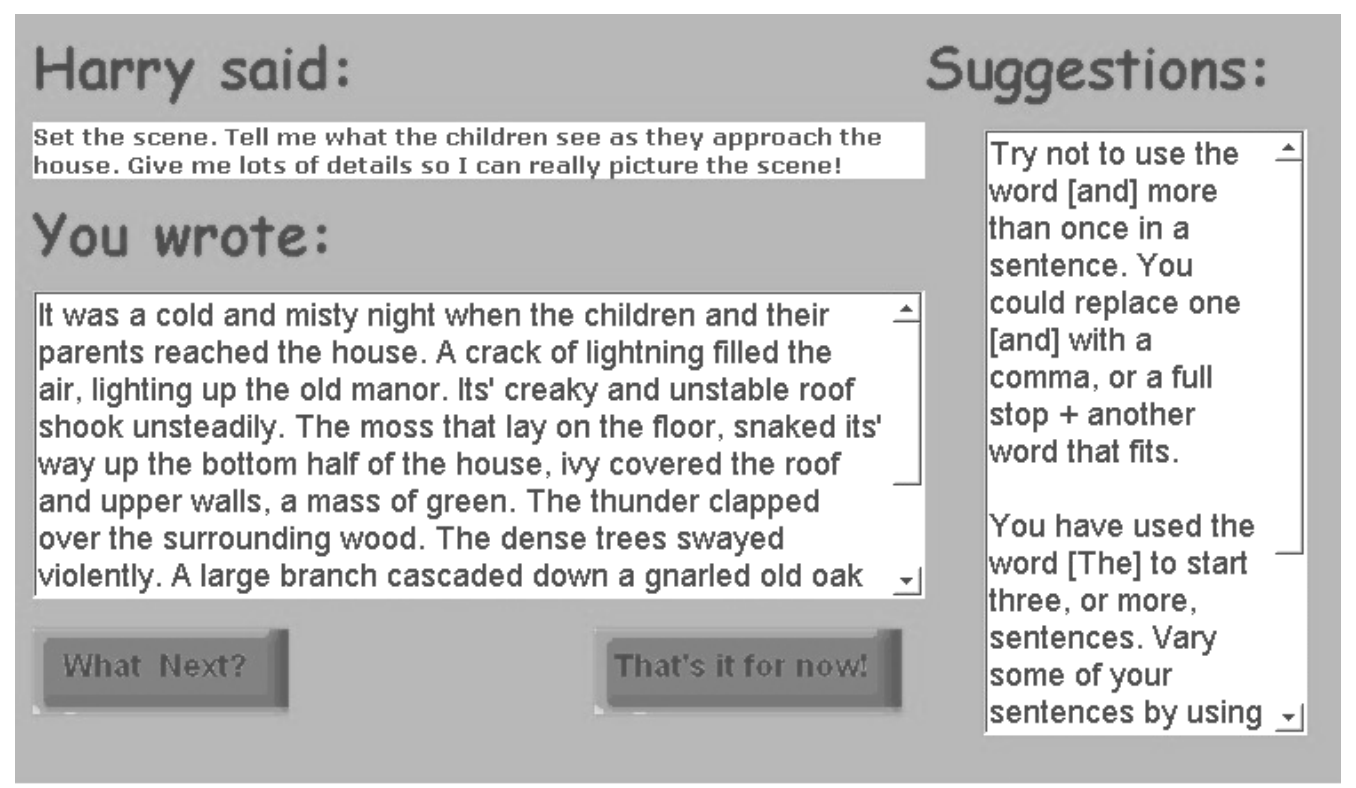

Figure 2. Stage 2: Editing Screen 
Working through the story section by section, in the order that the sections were written in, HARRY identifies places where the text can be improved grammatically and stylistically, and makes suggestions for how to make the improvements. It is anticipated that the child will proof read and make appropriate amendments to the text in the light of the advice. Three aspects of writing are commented upon at the editing stage: punctuation, vocabulary and sentence construction. Feedback suggestions drawn from these categories are then listed, in order to help children identify specific places where improvements can be made and how these could be effectively achieved. The children are expected to respond to each prompt on the list in turn. As with the composing section, the editing prompts are conversational in style.

With the editing feedback, it was not the intention to carry out a complete grammatical analysis, but to highlight some significant weaknesses which could be improved upon. The following section describes how HARRY detects grammar weaknesses and the prompts which are delivered as a consequence, suggest ways of achieving a more mature style. HARRY's suggestions for how to improve upon weaknesses, implement many of the teaching techniques outlined earlier (by for example, Shaughnessy and O'Hare).

\section{Punctuation}

Marking the end of sentences

HARRY indicates places in each section where full stops may have been omitted.

1. If more than 30 words are detected without a full stop, then the child is prompted to 'Check the long sentence beginning [...]. It may need breaking up into smaller sentences'. The child is expected to locate the 'long sentence', then use the technique of either pausing or intuition to find places where full stops could be correctly positioned. If a full stop, exclamation or question mark is missing at the end of the section, the prompt 'You have forgotten the full stop at the end of this paragraph' will be delivered.

2. Questions which are demarcated with full stops rather than question marks are identified. Sentences beginning with question words such as: Who, Where, What etc. which end with a full stop are detected, resulting in the prompt: 'Do you need a question mark at the end of the question beginning [Where]?

3. Minor sentences (one or two words) punctuated with full stops are highlighted, so that they can be replaced with exclamation marks, for example: 'The word [Hello] needs an exclamation mark after it!'

\section{Marking clause boundaries}

HARRY highlights places where commas might be used within sentences to separate clauses.

1. The co-ordinating connectives but, so, yet and then used within sentences (indicating compound sentences requiring a comma before the connective) are detected. For example, HARRY suggests 'You may need a comma before the word [but].

2. Sentences which begin with a single-word adverb (ending ly) such as 'Suddenly', which require a comma after the adverb are detected. HARRY also checks for other individual adverbs like: Also, Later, Next, First and Last; interjections like: Yes, No, Yeah, Well, Ah and $\mathrm{Oh}$; and connectives like: Yet, Also and So, used at the start of a sentence. If an adverb, an interjection or a connective is detected without a comma present at the start of a sentence, HARRY suggests 'You may need a comma after the word [Luckily]' etc.

3. HARRY detects long complex sentences where commas may have been omitted, by highlighting places where between 12 and 30 words are written without the presence of a comma, full stop, brackets or comma like words (and, because, or, that). HARRY then suggests 'Check the sentence beginning [...]. It may need commas. It is anticipated that 
having been alerted to the error, the child will use pausing or intuition to find appropriate places to position commas.

\section{Vocabulary}

HARRY checks for simple and frequently repeated words:

1. The simple words (One day, nice, big, said, went, walked, got, get, saw, ran, going, thing) are detected. Alternative, more sophisticated synonyms are offered, or the suggestion is made for the writer to think of an alternative for his/herself. For instance, HARRY suggests 'You have used the word [nice]. You could use a better word like [beautiful, delicious, enjoyable, interesting or exciting]', or 'You have used the word [get]. Try a better word or words'.

2. If the basic connectives also, so, then, but, because are repeatedly used in the whole text (more than a threshold of $0.8 \%$ of total words, a figure determined empirically) HARRY suggests: 'You use the word [so] a lot in your writing. Do you really need it?' etc.

3. If key words related to the story theme (journey, pirates, wood, space) are frequently repeated (more than a threshold of $0.8 \%$ of total words, a figure determined empirically) HARRY suggests for example: 'You use the word [pirates] a lot in your writing. Try another word, or words, like shipmates, gang, bloodthirsty crew, dastardly bunch'.

\section{Sentence construction}

1. HARRY detects where the basic connectives and, but, because, then and so have been used twice or more in a sentence, suggesting: 'Try not to use the word [and] more than once in a sentence. You could replace one [and] with a comma, or a full stop followed by another word that fits'.

2. Sentences that start with the same word three or more times in one section, are detected and then commented upon: 'You have used the word [...] to start three or more sentences. Can you think of a different way to start these sentences?'

3. HARRY detects a sequence of three or more simple sentences (where each sentence is between 8 and 12 words long), commenting: 'You have several short sentences in a row. For a better effect, link two of them together with a word like: if, with, when, how, except, while, although'.

4. HARRY detects a sequence of three or more consecutive long sentences (between 14 and 20 words) and comments: 'You have several long sentences in a row. Try breaking one of them into shorter sentences to vary them'.

To avoid unnecessary repetition of the editing prompts, if a child writes more than one sentence in a section containing several 'and's, uses the same words requiring a comma or a specific simple word which would be improved by substituting an alternative synonym several times etc, the prompts in these cases are presented only once. This effectively reduces the number of prompts delivered. It was considered that young children would feel disheartened if they were presented with too many 'corrections'. Although the prompts have been presented in this section according to the category they relate to, in practice, the prompts are programmed to be delivered in the order of first prompts requiring the child to identify long sections of text, then prompts requiring the child to scan the text in the search for individual words, as the latter was thought to be less tiring to do than the former. The following example list of prompts is typical of the order, number and variety of prompts presented to help a child edit one section of text, although the number and variety of prompts, varies according to the length of the text and kind of weaknesses evident within it. 
- Check the long sentence that begins ["First we'll show]. It may need breaking into shorter sentences with full stops.

- Try not to use the word [and] more than once in a sentence. You could replace one [and] with a comma, or a full stop followed by another word which fits.

- Do you need a question mark at the end of the question beginning [How]?

- You may need a comma after the word [Yes].

- You have used the word [ said ], try a better word like: suggested, whispered, joked, promised, interrupted, muttered or yelled.

HARRY is implemented on a Windows NT web server, using ASP scripts to communicate with a series of Microsoft Access databases. All interaction with HARRY is via a standard web browser and is therefore platform independent. Several JavaScripts are embedded within the HTML files downloaded to the client's web browser. These are used to check the number of words a child has written in a section and open up, and close, additional dialogue boxes. A cookie is written to the client's computer, after the story theme has been selected, which contains the story strategy that will be followed and this is used to store where the child is during the story should s/he, decide to leave finishing the writing for another occasion. When the child returns to continue a story, the cookie is checked; this provides a track of where within the strategy the child is, and authentication of the child. However, it does require that the child uses the same computer to write his/her story. The child's story is stored within an Access database on the web server. Separate databases are used for the first (composing) stage and the second (editing) stage. Thus, it was possible to separately assess the progress made by a child during both the composing and editing stages. Within the story theme databases, prompts are stored which are displayed according to the strategy of the story used together with the child's response made in previous sections. These are taken from the databases by the ASP scripts running on the server, and converted into HTML for downloading to the client's web browser. Likewise, the child's response is stored in his/her database using ASP scripts.

\section{Evaluation of the HARRY writing system upon children's written grammar and style}

Four case studies are presented to indicate the effects of the HARRY writing system upon children's writing performance. The children involved in the study were randomly selected from a mixed ability class of 8/9-year-olds, attending a co-educational, state-funded primary school. Each child wrote two stories on the same theme: a control story (written with a cutdown version of the system presenting a prompt suggesting a story theme and an accompanying reply box, but no further assistance) and a story written with the full assistance of HARRY. The data was collected over five weeks. Each child was permitted by the school to use HARRY for two literacy lessons a week, and they were allowed as many lessons as they needed to complete each story. The functions of the full HARRY system were demonstrated to the children before they started writing their assisted story. They were instructed to always consult all of the help buttons when embarking on a new section, leaving open the help option they considered most useful. It was explained that they should revisit the other help boxes and try to follow all the advice before moving on to the next section. The children were instructed to work through all the editing suggestions in the order they were presented. The effects of the system upon the children's writing performance are analysed through a quantitative analysis of the stories they produced, illustrated by examples of words, phrases and sentences where appropriate. 
A specially designed computer utility tool - CHECK TEXT - is used to provide the quantitative data concerning grammar and style features. A previous study in which quantitative analyses were performed upon a set of sample stories representing the range of ability levels associated with 11 year olds (Holdich, Holdich and Chung, 2002) has demonstrated that CHECK TEXT distinguishes strengths and weaknesses in 12 aspects of children's written grammar and style. CHECK TEXT is used to provide quantitative analyses for the control stories and for each of the three stages of the HARRY assisted stories. The tool provides analyses of twelve features covering story length, punctuation (full stops and comma use), sentence construction (use of basic connectives and simple sentence starters) and vocabulary (variety and sophistication). The twelve features are:

1. The total length of the story in words (as a measure of the amount of detail included);

2. The percentage of different words used in the first 100 words (as an indication of the extent of a child's vocabulary resources);

3. The number of 'and's used as a percentage of the total words (as an indication of the frequency of very basic compound sentence constructions);

4. The basic connectives but, so, then, because used as a percentage of the total words (as an indication of the frequency of basic compound sentence constructions);

5. The percentage of sentences started simply with a pronoun or the definite article (as an indication of the frequency of basic sentence constructions);

6. Average words per sentence (as an indication of the variety of sentence lengths and types);

7. Number of different words with more than 5 characters as a percentage of total words (as an indication of sophisticated vocabulary);

8. Number of adverbs as a percentage of total words (as an indication of sophisticated vocabulary);

9. Common verbs used (said, went, got, get, was, were) as a percentage of total number of words (as an indication of simple vocabulary);

10. Total common words (all common verbs and basic connectives identified above) as a percentage of total number of words (as an indication of simple vocabulary);

11. Mean words per sentence (as an indication of the correct use of full stops);

12. Commas used as a percentage of mean sentence length, excluding commas used in lists (as an indication of the presence of clauses within complex sentences demarcated by commas).

As the significance of the scores calculated for the stories written by the children involved in this study is not obvious without reference to the scores calculated for the original sample stories (presented in Holdich et al., 2002) three assessment categories were determined - poor, fair and good. The assessment boundaries are presented in Table 2. The scores together with the poor, fair and good reports, form the basis of the grammar and style comparisons for the stories reported in this paper. The CHECK TEXT data is illustrated by examples of specific words and phrases. 
Table 2. CHECK TEXT assessment boundaries

\begin{tabular}{|c|c|c|c|}
\hline CHECK TEXT feature & Poor & Fair & Good \\
\hline Total number of words & Less than 290 words & 290-390 words & $\begin{array}{l}\text { More than } 390 \\
\text { words }\end{array}$ \\
\hline Variety of words in first 100 & Less than $61 \%$ & $61 \%-67 \%$ & More than $67 \%$ \\
\hline Ands used to total words & More than $4.4 \%$ & $2.6 \%-4.4 \%$ & Less than $2.6 \%$ \\
\hline Common connectives & More than $2 \%$ & $1.5 \%-2 \%$ & Less than $1.5 \%$ \\
\hline Simple Sentence Starters & More than $50 \%$ & $37 \%-50 \%$ & Less than $37 \%$ \\
\hline Average sentence length & More than 16 words & 8-12 words & 12-16 words \\
\hline Number of words over 5 letters & Less than $13.5 \%$ & $13.5 \%-17 \%$ & More than $17 \%$ \\
\hline Common verbs used to total words & More than $5.5 \%$ & $4.2 \%-5.5 \%$ & Less than $4.2 \%$ \\
\hline Adverbs used to total words & Less than $0.7 \%$ & $0.7 \%-1.5 \%$ & More than $1.5 \%$ \\
\hline Common words to total words & More than $11.5 \%$ & $8.5 \%-11.5 \%$ & Less than $8.5 \%$ \\
\hline $\begin{array}{l}\text { Mean words per sentence (use of } \\
\text { full stops) }\end{array}$ & More than 18 words & 14-18 words & 8-14 words \\
\hline Sentence length to commas ratio & More than 2 & $1-2$ & Less than 1 \\
\hline
\end{tabular}

\section{James}

The CHECK TEXT scores for both stories (including each stage) are presented in Table 3. The 'good' reports for the control story and third stage of the HARRY assisted story are highlighted.

Table 3. CHECK TEXT scores and reports for James' stories

\begin{tabular}{|c|c|c|c|c|c|c|c|c|}
\hline James & \multicolumn{2}{|c|}{ Control } & \multicolumn{2}{|c|}{$1^{\text {st }}$ stage } & \multicolumn{2}{|c|}{$2^{\text {nd }}$ stage } & \multicolumn{2}{|c|}{$3^{\text {rd }}$ Stage } \\
\hline Feature & \multicolumn{2}{|c|}{ score/report } & \multicolumn{2}{|c|}{ score/report } & \multicolumn{2}{|c|}{ score/report } & \multicolumn{2}{|c|}{ score/report } \\
\hline Total number of words & 454 & Good & 560 & Good & 536 & Good & 530 & Good \\
\hline $\begin{array}{l}\text { Variety of words in } \\
\text { first } 100\end{array}$ & $63 \%$ & Fair & $65 \%$ & Fair & $72 \%$ & Good & $69 \%$ & Good \\
\hline $\begin{array}{l}\text { Ands used to total } \\
\text { words }\end{array}$ & $4.2 \%$ & Fair & $7.1 \%$ & Poor & $4.7 \%$ & Poor & $4.7 \%$ & Poor \\
\hline Common connectives & $5.3 \%$ & Poor & $2.1 \%$ & Poor & $2.6 \%$ & Poor & $2.6 \%$ & Poor \\
\hline $\begin{array}{l}\text { Simple sentence } \\
\text { starters }\end{array}$ & $32.4 \%$ & Good & $20.8 \%$ & Good & $19.4 \%$ & Good & $22.9 \%$ & Good \\
\hline $\begin{array}{l}\text { Average sentence } \\
\text { length in words }\end{array}$ & 13.4 & Good & 23.3 & Poor & 17.3 & Poor & 15.1 & Good \\
\hline $\begin{array}{l}\text { Number of words over } \\
5 \text { letters }\end{array}$ & $12.3 \%$ & Poor & $13.4 \%$ & Poor & $15.9 \%$ & Fair & $16.2 \%$ & Fair \\
\hline $\begin{array}{l}\text { Common verbs used to } \\
\text { total words }\end{array}$ & $5.9 \%$ & Poor & $2.7 \%$ & Good & $1.3 \%$ & Good & $1.3 \%$ & Good \\
\hline
\end{tabular}




\begin{tabular}{|l|l|l|l|l|l|l|l|l|}
\hline $\begin{array}{l}\text { Adverbs used to total } \\
\text { words }\end{array}$ & $0.2 \%$ & Poor & $0.2 \%$ & Poor & $0.4 \%$ & Poor & $0.6 \%$ & Poor \\
\hline $\begin{array}{l}\text { Common words to total } \\
\text { words }\end{array}$ & $15.4 \%$ & Poor & $12 \%$ & Poor & $8.6 \%$ & Fair & $8.7 \%$ & Fair \\
\hline $\begin{array}{l}\text { Mean words per } \\
\text { sentence }\end{array}$ & 13.4 & Good & 23.3 & Poor & 17.3 & Fair & 15.1 & Fair \\
\hline $\begin{array}{l}\text { Sentence to comma } \\
\text { ratio }\end{array}$ & 2.7 & Poor & 1.8 & Fair & 0.9 & Good & 0.7 & Good \\
\hline
\end{tabular}

The CHECK TEXT scores for James' control story reveal a strength in punctuating sentences with full stops (mean sentence length $=13.4$ words). The scores reveal James' weakness is vocabulary, which is simple and unvaried (variety $=63 \%$, common words $=15.4 \%$, number of words $>5$ letters $=12.3 \%$, common verbs $=5.9 \%$, adverbs $=0.2 \%$ ). The lack of commas (sentence to comma ratio $=2.7$ ) either indicates the presence of few complex sentences or incorrectly demarcated complex sentences. Closer examination of the text indicates that the majority of sentences are simple or compound constructions, suggesting that James is most secure with these basic sentence structures. James relies upon basic sentence connectives (total $=9.5 \%$, ands $=4.2 \%$, common connectives $=5.3 \%$ ). CHECK TEXT indicates that James varies the way he starts sentences. Only one third (32.4\%) of James' sentences begin with pronouns or the definite article. However, James also starts a third of sentences with the connectives 'So' and 'Then', not counted by CHECK TEXT. Adding the use of these basic connectives to start sentences to other simple sentence starters reveals how James starts two thirds of his sentences in a similar way, using the most basic of constructions.

CHECK TEXT recorded two more 'good' reports for the assisted story (final draft) than the control. The scores for James' HARRY assisted story indicate that vocabulary (variety and sophistication) is improved (variety $=69 \%$, words $>5$ letters $=16.2 \%$, common verbs $=$ $1.3 \%$, common words $=8.7 \%$ ). Adventurous words such as, invisibility, exploring, obstacle, noticed, courtiers, retrieve, revived, clutched are used. Sentence construction is also more varied. Sentences are started in more sophisticated ways (simple sentence starters $=22.9 \%$ ) and fewer common connectives are used (2.6\%) although there is a similar proportion of 'and's (4.7\%). The higher number of words per sentence indicates a greater variety of sentence types. The presence of some complex constructions is indicated by the good sentence to comma ratio (0.7).

That fact that the composing prompts at the first stage did not cause James to use many more adventurous words is reflected in the CHECK TEXT scores. The scores for variety of vocabulary, adverbs and common words were similar to the control story. At the first stage, CHECK TEXT recorded a similar score to the control for 'long words' (13.4\%) but this score was improved to $15.9 \%$ at the editing stage. James' average sentence length increased by 10 words per sentence between the control story and the first stage, indicating much poorer use of full stops. The percentage of ands used at the end of the first stage (7.1\%), a figure 3\% higher than the control story, indicated that James was also relying more heavily upon very basic sentence constructions. These worse scores were due to the difficulty James experienced with expanding sentences to include adjectives and descriptive phrases. His solution was to write long sentences, linking descriptions with the connective 'and', for example:

'The ceiling is tiled and there are marble walls and a gold shining statues and a pool the size of a football pitch and in a locked room there is an invisabilete (invisibility) cloak (there are only three of them in the univers (universe).' 
At the editing stage, James improved his sentence constructions:

'The ceiling is tiled. There are marble walls, a gold shining statue and a pool the size of a football pitch. In a locked room there is an invisabilete (invisibility) cloak (there are only three of them in the univers (universe).'

After the editing stage, the percentage of ands dropped from $7.1 \%$ to $4.7 \%$, a similar score to that achieved by the control story (4.2\%). Although James had improved his sentence constructions considerably, the poor report for use of 'and' indicated the prevailing dependence upon basic sentence constructions. However, reducing the occurrences of the connective 'and' helped improve the score for variety of vocabulary, which increased by $7 \%$ at the second stage. Replacing some 'and's with a full stop also helped to improve his mean words per sentence from 23.3 to 17.3.

To summarise, with HARRY's assistance James improved upon the variety of words, used fewer basic words and more long words, demonstrated a greater variety of sentence structures and punctuated clauses within complex sentences more frequently with commas. However, reviewing and revising vocabulary choice and sentence structure during the first stage had a negative effect upon his use of full stops and the connective 'and' - a result consistent with Karmiloff-Smith's (1992) research, noted earlier, that children's attempts to improve their writing can result in a drop in quality. Although James improved upon these scores at the second stage, the reports he achieved for these features were worse for the HARRY assisted story than for the control.

\section{Sophie}

The CHECK TEXT scores for both stories (including each stage) are presented in Table 4. The 'good' reports for the control story and third stage of the HARRY assisted story are highlighted.

Table 4. CHECK TEXT scores and reports for Sophie's stories

\begin{tabular}{|l|l|l|l|l|l|l|l|l|}
\hline Sophie & \multicolumn{2}{|l|}{ Control } & \multicolumn{2}{l|}{$\mathbf{1}^{\text {st }}$ stage } & \multicolumn{2}{l|}{$2^{\text {nd }}$ stage } & \multicolumn{2}{l|}{$3^{\text {rd }}$ Stage } \\
\hline Feature & \multicolumn{2}{|l|}{ score/report } & \multicolumn{2}{l|}{ score/report } & \multicolumn{2}{l|}{ score/report } & \multicolumn{2}{l|}{ score/report } \\
\hline Total number of words & 376 & Fair & 658 & Good & 676 & Good & 663 & Good \\
\hline $\begin{array}{l}\text { Variety of words in first } \\
100\end{array}$ & $76 \%$ & Good & $79 \%$ & Good & $79 \%$ & Good & $78 \%$ & Good \\
\hline Ands used to total words & $2.4 \%$ & Good & $3.5 \%$ & Fair & $3.1 \%$ & Fair & $3.2 \%$ & Fair \\
\hline Common connectives & $1.9 \%$ & Fair & $1.7 \%$ & Fair & $0.9 \%$ & Good & $1.1 \%$ & Good \\
\hline Simple sentence starters & $18.2 \%$ & Good & $22.2 \%$ & Good & $21.6 \%$ & Good & $31.7 \%$ & Good \\
\hline $\begin{array}{l}\text { Average sentence length } \\
\text { in words }\end{array}$ & 17.1 & Poor & 36.6 & Poor & 18.3 & Poor & 16.2 & Poor \\
\hline $\begin{array}{l}\text { Number of words over } 5 \\
\text { letters }\end{array}$ & $16 \%$ & Fair & $18.1 \%$ & Good & $18.6 \%$ & Good & $18.3 \%$ & Good \\
\hline $\begin{array}{l}\text { Common verbs used to } \\
\text { total words }\end{array}$ & $4.3 \%$ & Fair & $4.7 \%$ & Fair & $4 \%$ & Good & $4.1 \%$ & Good \\
\hline $\begin{array}{l}\text { Adverbs used to total } \\
\text { words }\end{array}$ & $0.8 \%$ & Fair & $1.7 \%$ & Good & $1.9 \%$ & Good & $1.8 \%$ & Good \\
\hline
\end{tabular}




\begin{tabular}{|l|l|l|l|l|l|l|l|l|}
\hline $\begin{array}{l}\text { Common words to total } \\
\text { words }\end{array}$ & $8.5 \%$ & Fair & $9.9 \%$ & Fair & $8 \%$ & Good & $8.3 \%$ & Good \\
\hline Mean words per sentence & 17.1 & Fair & 36.6 & Poor & 18.3 & Poor & 16.2 & Fair \\
\hline Sentence to comma ratio & 2.8 & Poor & 7.3 & Poor & 1.5 & Fair & 1.1 & Fair \\
\hline
\end{tabular}

The scores for Sophie's control story reveal a strength in vocabulary - both variety and sophistication - (variety $=76 \%$, words $>5$ letters $=16 \%$, adverbs $=0.8 \%$, common verbs $=$ $4.3 \%$, common words $=8.5 \%$ ) for example: 'surrounded, decided, insisted, normally, destroyed, trusted'. Her story shows evidence of the beginnings of mature sentence constructions (simple sentence starters $=18.2 \%$, total basic connectives $=4.3 \%$, of which $2.4 \%=$ the connective and). The story is reasonably detailed (376 words). CHECK TEXT reveals Sophie's weakness is in punctuation (average sentence length $=17.1$ words, sentence to comma ratio $=2.8$ ). By inserting full stops correctly in her text, her average sentence length is reduced to 8.2 words and sentence to comma ratio is improved to 0.7. Whilst the presence of commas indicates the presence of complex sentences (e.g. 'Not for me, I was too old'), the very low number of words per sentence indicates that Sophie writes using mostly simple sentences, although she varies the way she starts them (simple sentence starters $=10.9 \%$ ).

CHECK TEXT awarded Sophie's HARRY assisted story (final draft) five more good reports than her control story. The HARRY assisted story is very detailed (663 words). Improvements have been made with vocabulary choice (variety $=78 \%$, words $>5$ letters $=$ $18.3 \%$, common verbs $=4.1 \%$, common words $=8.3 \%$, adverbs $=1.8 \%$ ). Many sophisticated words are used such as 'interrupted, approached, gigantic, hurtled, muttered, whispered, bravely, proudly'. More, but not all sentences are correctly punctuated (mean sentence length $=16.2$, sentence to comma ratio $=1.1$ ). Closer examination of the text reveals evidence of more deliberate control with sentence structure - using simple and minor sentence structures for dramatic effect, for example 'We came to a dead end ... He understood us ...They pounced'. Complex sentences containing several clauses are constructed, for example, 'Daniel was so excited that he crouched down and vanished down the hole before you could say stiganopithicus'. A weakness with punctuation is still evident however. There are many places where full stops (including question marks) and commas have been omitted, for example:

'The weird creature came out of the cave. He was 10 feet hight (high) he let out an oooohhhhhhhhhhhh imedeatly (immediately) the wolves fled with feir (fear)'.

The first stage had a noticeably negative effect upon Sophie's punctuation. Her CHECK TEXT score after the first stage for mean sentence length (36.6 words) was twice that of the control story (17.1), indicating much poorer use of full stops, and she used proportionally fewer commas to demarcate clauses than in the control story (sentence to comma ratio $=7.3$ compared to 2.8 in the control). Reflecting about vocabulary seemed to have caused her to forget to punctuate her sentences. The editing suggestions at the second stage, helped Sophie improve her punctuation to a level similar to that demonstrated in the control story, but did not help her improve her punctuation sufficiently to achieve a 'good' report, as many sentences remained poorly punctuated.

To summarise, HARRY particularly helped Sophie improve upon her vocabulary choice (variety and sophistication). Comparison of the control story and the final draft of the HARRY assisted story indicates a lack of improvement in Sophie's use of full stops. However, reviewing and revising vocabulary during the first stage had had a negative effect 
upon Sophie's punctuation. Although Sophie improved her scores for punctuation considerably during the second stage, the improvement is not evident in the final score and report for use of full stops, when compared to her control story.

\section{Tom}

The CHECK TEXT scores for both stories (including each stage) are presented in Table 5. The 'good' reports for the control story and third stage of the HARRY assisted story are highlighted.

Table 5. CHECK TEXT scores and reports for Tom's stories

\begin{tabular}{|c|c|c|c|c|c|c|c|c|}
\hline Tom & \multicolumn{2}{|c|}{ Control } & \multicolumn{2}{|c|}{$1^{\text {st }}$ stage } & \multicolumn{2}{|c|}{$2^{\text {nd }}$ stage } & \multicolumn{2}{|c|}{$3^{\text {rd }}$ Stage } \\
\hline Feature & \multicolumn{2}{|c|}{ score/report } & \multicolumn{2}{|c|}{ score/report } & \multicolumn{2}{|c|}{ score/report } & \multicolumn{2}{|c|}{ score/report } \\
\hline Total number of words & 306 & Fair & 1096 & Good & 1099 & Good & 1098 & Good \\
\hline $\begin{array}{l}\text { Variety of words in } \\
\text { first } 100\end{array}$ & $66 \%$ & Fair & $76 \%$ & Good & $75 \%$ & Good & $73 \%$ & Good \\
\hline $\begin{array}{l}\text { Ands used to total } \\
\text { words }\end{array}$ & $2.3 \%$ & Good & $4.1 \%$ & Fair & $2.8 \%$ & Fair & $2.7 \%$ & Fair \\
\hline Common connectives & $4.2 \%$ & Poor & $3.3 \%$ & Poor & $2 \%$ & Fair & $2.2 \%$ & Poor \\
\hline $\begin{array}{l}\text { Simple sentence } \\
\text { starters }\end{array}$ & $40 \%$ & Fair & $31.4 \%$ & Good & $29.5 \%$ & Good & $31 \%$ & Good \\
\hline $\begin{array}{l}\text { Average sentence } \\
\text { length in words }\end{array}$ & 30.6 & Poor & 21.5 & Poor & 13.9 & Good & 12.6 & Good \\
\hline $\begin{array}{l}\text { Number of words over } \\
5 \text { letters }\end{array}$ & $15 \%$ & Fair & $16.5 \%$ & Fair & $18.8 \%$ & Good & $17.7 \%$ & Good \\
\hline $\begin{array}{l}\text { Common verbs used to } \\
\text { total words }\end{array}$ & $6.2 \%$ & Poor & $4.1 \%$ & Good & $2.3 \%$ & Good & $2.3 \%$ & Good \\
\hline $\begin{array}{l}\text { Adverbs used to total } \\
\text { words }\end{array}$ & $0 \%$ & Poor & $0.5 \%$ & Poor & $0.7 \%$ & Fair & $0.7 \%$ & Fair \\
\hline $\begin{array}{l}\text { Common words to total } \\
\text { words }\end{array}$ & $12.7 \%$ & Poor & $11.5 \%$ & Fair & $7.1 \%$ & Good & $7.2 \%$ & Good \\
\hline $\begin{array}{l}\text { Mean words per } \\
\text { sentence }\end{array}$ & 30.6 & Poor & 21.5 & Poor & 13.9 & Good & 12.6 & Good \\
\hline $\begin{array}{l}\text { Sentence to comma } \\
\text { ratio }\end{array}$ & 6.1 & Poor & 21.5 & Poor & 0.4 & Good & 0.3 & Good \\
\hline
\end{tabular}

The CHECK TEXT scores indicate that the control story is reasonably detailed (306 words). Tom has progressed from using the most basic of sentence connectives (number of 'ands' used $=2.3 \%$ ), but relies quite heavily upon other basic connectives (common connectives $=4.2 \%$ ). Nevertheless, Tom writes some mature complex sentence constructions (e.g. The king was suffering from a type of aneserier (sic) a kind of sickness that could kill you). Tom uses a reasonable variety of words (66\%) and some of his vocabulary is sophisticated (words $>5$ letters $=15 \%$ ) such as: suffering, honour, informed, hurried, obstacle, complete, instincts, boulder, sprinted. CHECK TEXT reveals weaknesses in punctuation (mean number of words per sentence $=30.6$, sentence to comma ratio $=6.1$ ) and vocabulary. Although there is a reasonable variety of words and some sophisticated vocabulary, there is a high proportion of simple words (common words $=12.7 \%$, common verbs $=6.2 \%$ ) and the writing lacks adverbs (0\%). 
The CHECK TEXT scores indicate that improvements have been made in the HARRY assisted story (final draft) to all aspects apart from use of the connective 'and'. The HARRY assisted story achieved nine 'good' reports, whereas the control achieved just one. The assisted story is very detailed (1098 words). Vocabulary is sophisticated such as 'sparkling, ordered, retrieve, decided, spotted, performances, culprit, pursuit, panicked, produced' etc. (variety = $73 \%$, words $>5$ letters $=17.7 \%$, common words $=7.2 \%$, common verbs $=2.3 \%$, adverbs $=$ $0.7 \%$ ). The writing contains a variety of sentence structures (simple sentence starters $=31 \%$ ). For example, 'It was clearly a magician who lived there because he had robes on.' And "By order of King Robert, somebody has to surch (search) for the fabled healing stone". Sentences are mostly accurately demarcated with full stops (mean words per sentence $=12.6$ ) and commas (sentence to commas ratio $=0.3$ ). A reliance upon common connectives (common connectives used $=2.2 \%$ ) is the only remaining weakness.

Many improvements were initiated during the first stage, with further improvements being made at the second stage. However, there were exceptions to this pattern. Tom's dependence upon the connective 'and' and lack of commas increased during the first stage. Tom improved upon both aspects during the second stage, but whilst the 'good' report achieved for comma use reflected the considerable improvement that had been made, the final report for use of the connective 'and' was worse than for the control story.

\section{Stephanie}

The CHECK TEXT scores for both stories (including each stage) are presented in Table 6. The 'good' reports for the control story and third stage of the HARRY assisted story are highlighted.

Table 6. CHECK TEXT scores and reports for Stephanie's stories

\begin{tabular}{|c|c|c|c|c|c|c|c|c|}
\hline Stephanie & \multicolumn{2}{|c|}{ Control } & \multicolumn{2}{|c|}{$\mathbf{1}^{\text {st }}$ stage } & \multicolumn{2}{|c|}{$2^{\text {nd }}$ stage } & \multicolumn{2}{|c|}{$3^{\text {rd }}$ Stage } \\
\hline Feature & \multicolumn{2}{|c|}{ score/report } & \multicolumn{2}{|c|}{ score/report } & \multicolumn{2}{|c|}{ score/report } & \multicolumn{2}{|c|}{ score/report } \\
\hline Total number of words & 570 & Good & 871 & Good & 866 & Good & 866 & Good \\
\hline $\begin{array}{l}\text { Variety of words in } \\
\text { first } 100\end{array}$ & $59 \%$ & Poor & $60 \%$ & Poor & $60 \%$ & Poor & $59 \%$ & Poor \\
\hline $\begin{array}{l}\text { Ands used to total } \\
\text { words }\end{array}$ & $4.7 \%$ & Poor & $3.8 \%$ & Fair & $3.3 \%$ & Fair & $3.2 \%$ & Fair \\
\hline Common connectives & $1.1 \%$ & Good & $0.7 \%$ & Good & $0.5 \%$ & Good & $0.4 \%$ & Good \\
\hline $\begin{array}{l}\text { Simple sentence } \\
\text { starters }\end{array}$ & $31.1 \%$ & Good & $20.5 \%$ & Good & $21.5 \%$ & Good & $24.1 \%$ & Good \\
\hline $\begin{array}{l}\text { Average sentence } \\
\text { length in words }\end{array}$ & 12.7 & Good & 12.8 & Good & 11.4 & Fair & 10.8 & Fair \\
\hline $\begin{array}{l}\text { Number of words over } \\
5 \text { letters }\end{array}$ & $10.5 \%$ & Poor & $11.8 \%$ & Poor & $13.4 \%$ & Poor & $13.1 \%$ & Poor \\
\hline $\begin{array}{l}\text { Common verbs used to } \\
\text { total words }\end{array}$ & $4.9 \%$ & Fair & $4.6 \%$ & Good & $1.4 \%$ & Good & $1.5 \%$ & Good \\
\hline $\begin{array}{l}\text { Adverbs used to total } \\
\text { words }\end{array}$ & $1.6 \%$ & Good & $0.7 \%$ & Fair & $0.7 \%$ & Fair & $0.8 \%$ & Fair \\
\hline $\begin{array}{l}\text { Common words to total } \\
\text { words }\end{array}$ & $10.7 \%$ & Fair & $9 \%$ & Fair & $5.1 \%$ & Good & $5 \%$ & Good \\
\hline $\begin{array}{l}\text { Mean words per } \\
\text { sentence }\end{array}$ & 12.7 & Good & 12.8 & Good & 11.4 & Good & 10.8 & Good \\
\hline $\begin{array}{l}\text { Sentence to comma } \\
\text { ratio }\end{array}$ & 4.2 & Poor & 2.7 & Poor & 0.4 & Good & 0.3 & Good \\
\hline
\end{tabular}


The CHECK TEXT scores indicate that Stephanie's strength in the control story is with sentence construction and with punctuating sentences with full stops. She understands the structure of a complete sentence as she positions full stops accurately (mean words per sentence $=12.7$ words). There is some variation in sentence structure (average sentence length $=12.7$ words, simple sentence starters $=31.1 \%$ ). There is evidence of some complex sentence constructions, for example 'They travelled east until the sun set then they set up camp', although she does not display their grammatical structure with commas (sentence to comma ratio $=4.2)$. The scores indicate a general weakness with vocabulary, both variety $(59 \%)$ and sophistication (number of words $>5$ letters $=10.5 \%$, common words $=10.7 \%$, common verbs $=4.9 \%$ ) although she makes good use of adverbs $(1.6 \%)$ for example, immediately, finally, probably, honestly. Stephanie relies on the connective 'and' (4.7\%) suggesting a predominance of compound sentences.

The HARRY assisted story (final draft) is much more detailed (866 words) demonstrating fewer simple words (common words $=5 \%$, common verbs $=1.5 \%$ although words $>5$ letters $=13.1 \%$ and adverbs $=0.8 \%$ ), but no improvement in variety (variety $=59 \%$ ). Sentence construction is also improved. Sentences are started in a greater variety of ways (24.1\%) and fewer basic connectives are used (ands $=3.2 \%$, common connectives $=0.4 \%$ ). Although the average sentence length of 10.8 words indicates the presence of many short, simple sentences, the sentence to comma ratio of 0.3 , indicates some are mature complex constructions. These include: 'Just as they started quarrelling, an old lady came by and asked them what was wrong ... Suddenly, there was a flash of lightning followed by two enormous rumbles'.

To summarise, with the control story, Stephanie demonstrated an understanding of sentence construction - she punctuated sentences accurately with full stops, although she relied upon the connective 'and', indicating a predominance of basic compound sentences. She demonstrated a weakness with vocabulary - both variety and sophistication. The HARRY assisted story demonstrated improved sentence construction, use of commas and fewer simple words, although the scores for variety and sophistication of vocabulary remained consistently poor. Stephanie's limited improvement with vocabulary is consistent with Shaughnessy's (1977) research quoted earlier, which indicated the stubborn and individually different limits to the pace at which words enter pupils' active vocabulary.

\section{Conclusion}

Teachers usually provide children with advice and feedback in order to assist them to revise, and edit. Providing comments is a time consuming task, requiring knowledge of significant weaknesses to focus upon and strategies that will result in appreciable improvements. Analysis of the stories written by the four children involved in this study suggests that HARRY offered effective revision strategies, and systematically and successfully guided the children through the processes of detection, identification and correction of grammar and style weaknesses. The HARRY assisted stories were better than the controls. They contained more adventurous and varied vocabulary, evidenced by a higher percentage of words longer than 5 letters, a higher percentage of different words used in the first 100 and a lower percentage of common words. Sentence constructions were more sophisticated, evidenced by a lower percentage of common connectives, particularly the connective 'and', and a lower percentage of sentences starting with pronouns and the definite article. Full stops were used more accurately, evidenced by fewer words per sentence and more commas were used to demarcate the clauses in complex sentences, evidenced by a smaller ratio of words to 
commas. However, comparisons of the control and assisted stories (final stage) sometimes indicated that the children apparently either made no improvement in some specific features or that performance in some aspects deteriorated with HARRY's assistance. That the process of improvement in some grammar and stylistic features can result in an apparent drop in the quality of others, presents a problem when evaluating the efficiency of a system, using a wholly numerical approach. A holistic approach, such as case study, provides greater insight into the process of challenging children to write using more adventurous and sophisticated vocabulary and sentence construction etc. Reflecting upon HARRY's revising suggestions at the first stage resulted in improvements being made to some features, such as vocabulary, but the process sometimes caused poorer performance in others, such as punctuation and use of the connective 'and'. This effect was caused either by the child trying to implement writing techniques without understanding how to apply them successfully, or by the child paying more attention to certain aspects, causing the child to forget to pay attention to others. However, many of the features that deteriorated during the composing/revising stage were improved upon at the editing stage. Separate analysis of the stages revealed the idiosyncratic pattern of improvement exhibited by each child.

\section{References}

Bartlett, E.J. (1982). Learning to revise: some component processes. In Nystrand, M. What writers know. The language, process and structure of written discourse. London: Academic Press.

Bereiter, C. and Scardamalia, M. (1983). Does learning to write have to be so difficult? In Freedman, A., Pringle, I. and Yalden, J. (Eds). Learning to write: first language/second language. London: Longman.

Bereiter, C. and Scardamalia, M. (1987). The psychology of written composition. Lawrence Erlbaum. New Jersey: Hillsdale.

Cordeiro, P., Giacobbe, M. and Cazden, C. (1983). Apostrophes, quotation marks and periods: learning punctuation in the first grade. Language Arts, 60, 323-32.

Crystal, D. (1995). The Cambridge encyclopaedia of the English language. Cambridge: Cambridge University Press.

Daiute, C. (1985). Writing and computers. Massachusetts: Addison-Wesley.

Flower, L. and Hayes, J. (1981). A cognitive process theory of writing, College Composition and Communication, 32, 365-386.

Hall, N. (1998). Young children and resistance to punctuation. Research in Education No.60, 29-39.

Harpin, W. (1976). The second 'R'. London: Allen and Unwin.

Hillocks, G. (1982). The interaction of instruction, teacher comment and revision in teaching the composing process. Research in the Teaching of English, 16, 261-78.

Holdich, C.E. Holdich, R.G. and Chung, P.W.H. (2002). Assessing aspects of children's written grammar: automating the process. Computers and Education, 39, 37-50. 
Karmiloff-Smith, A. (1992). Beyond modularity: a developmental perspective on cognitive science. Cambridge, Mass: MIT Press.

Kress, G. (1994). Learning to write, $2^{\text {nd }}$ edition. London: Routledge and Kegan.

O'Hare F. (1973). Sentence combining: improving student writing without formal grammar instruction. Illinois: National Council of Teachers of English.

Murray, D. (1984). Write to learn. New York: Holt Rinehart Winston.

Perera, K. (1984). Children's writing and reading. Oxford: Blackwell.

Piaget, J. (1926). The language and thought of the child. London: Routledge and Kegan.

Potter, P. (1994). Word processors, redrafting and the niche of the laptop. In Wray, D. and Medwell, J. Teaching Primary English. The state of the art. London: Routledge.

Robertson, J. and Wiemer-Hastings, P. (2002). Feedback on children's stories via multiple interface agents. Proceedings of the international conference on intelligent tutoring systems. Biarritz, France.

Robinson, A. (1996). Conversations with teachers about punctuation, In Hall, N. and Robinson, A. (Eds). Learning about punctuation. Clevedon, England: Multilingual Matters.

Sharples, M. (1999). Writing as creative design. London: Routledge.

Shaughnessy, M.P. (1977). Errors and expectations. New York: Oxford University Press.

Smith, F. (1982). Writing and the writer. London: Heinemann Educational.

The National Writing Project (1990). Writing and micros. Surrey: Nelson.

Tomlinson, D (1994). Errors in the research into the effectiveness of grammar teaching, English in Education, 28, 20-26.

Trushell, J.M. (1986), Llanfairpwyllgwyngyllgogerychwyrndrobwllllantsiliogogogoch Redrafted. In Trushell, J., The moving cursor. Word processing applications in the language classroom. Proceedings from a symposium held at the NFER in Autumn 1986. Centre for Research in Language and Communication.

Wilkinson, A (1971) The foundation of language. Oxford University Press, Oxford. 